\title{
Volatility spillovers and time-frequency correlations between Chinese and African stock markets
}

\author{
Ngo Thai Hung This study examines the volatility spillovers in \\ University of Finance-Marketing, \\ Ho Chi Minh City, \\ Vietnam \\ E-mail: hung.nt@ufm.edu.vn \\ time and frequency from China to five frontier \\ stock markets in Africa (Kenya, Mauritius, \\ Tunisia, Morocco and Nigeria). The authors \\ consider the volatility spillover after the global \\ financial crisis. A bivariate Generalized \\ Autoregression Conditional Heteroscedasticity- \\ Baba, Engle, Kraft and Kroner (GARCH- \\ $\mathrm{BEKK}$ ) model and wavelet coherence analysis \\ are combined to obtain volatility spillover \\ effects and time-frequency correlations. \\ Empirical results reveal evidence of significant \\ volatility spillovers between China and the five \\ African stock markets, as well as time- \\ Keywords: \\ volatility spillover, \\ GARCH-BEKK, \\ wavelet coherence, \\ erence, positive signs for foreign investors to diversify \\ African stock markets \\ frequency correlations for different market \\ pairs. In general, wavelet coherence findings \\ suggest that in most pairs, the China market \\ was leading. Therefore, these results are \\ their portfolio among China's and its trading \\ partners' stock markets.
}

\section{Introduction}

The increasing interdependency and market co-movement of stock markets among various countries have been examined in recent years because of globalization, liberalization of financial markets and international economic integration. These phenomena are causing international financial markets to become more correlated and connected than ever before. A better understanding of the connectedness and association among divergent financial markets is indispensable for global investors, financial institutions and governments (Zhou-Zhang 2012). In addition, it is necessary to fully comprehend the volatility spillover effects and time-frequency correlations of different regional integrations to better forecast stock return dynamics and outline mechanism to reduce financial risks. According to Ahmed and Huo (2018), greater stock market integration and financial cooperation result in policy changes and economic vulnerabilities unless the process is assisted by strengthened market institutions. In particular, the global financial crisis provides evidence that global stock markets are more likely to be interdependent and

Regional Statistics, Vol. 10. No. 2. 2020: 63-82; DOI: 10.15196/RS100203 
influence the dynamics of investors' portfolio diversification behavior and financial stability of countries.

According to Sznajderska (2019), China plays a prominent role both in conventional international trade and in global supply chains, dealing with intermediate goods and re-exporting them to other regions. As a result, for some countries, the direct effects of the slowdown in the Chinese economy would be minor, whereas the indirect influences, primarily through its partners, might be significant. In recent years, China's engagement in Africa has been growing exponentially in many aspects such as trade, investment and aid (Donou-AdonsouLim 2018). The China-Africa relationship, which some people term win-win, is destined to help not only China (known as a fast-growing economy), but also African nations in terms of growth and development. As a result, early literature centres on the correlations between China and African financial markets (see for example: Alden 2005, Raphael et al. 2007, Gu 2009, Naidu-Mbazima 2008, Hung 2019b). The cited studies put forward that China has a substantial effect on African countries and has been building a powerful African partnership. This study is also stimulated by the fact that African economies are the primary recipients of Chinese foreign investment flows and are among the major international producers of oil and minerals.

In the last 20 years, with the development of emerging financial markets, many authors have become increasingly interested in the connectedness between emerging and developed markets. Several previous studies argue that increasing bilateral trade relations between countries can have a considerable effect on their stock market linkages. (Isakov-Pérignon 1999, Koutmos-Booth 1995, CheungWestermann 2001, Béres et al. 2019).

\section{Literature review}

Recent literature focuses on the correlations between China and other financial markets. For example, Kirkulak Uludag and Khurshid (2019) examine volatility spillover from the Chinese stock market to E7 and G7 stock markets using vector autoregression generalized autoregressive conditional heteroskedasticity (VARGARCH) frameworks. The results indicate significant volatility spillover from the Chinese stock market to the E7 and G7 stock markets, especially the highest volatility spillover occurs between China and Japan among G7 countries. Lee (2019) employs panel unit root tests and panel cointegration tests to investigate the common trends among Asian financial markets. The study shows that financial market returns among Asian countries are all stationary and panel unit root tests reinforce this conclusion, in particular, the Chinese financial market is not in sync with any other Asian financial markets through the sample period. Fang and Bessler (2018) empirically study whether China leads the downward co-movement in other

Regional Statistics, Vol. 10. No. 2. 2020: 63-82; DOI: 10.15196/RS100203 
Asian markets during the 2015 China crash using a data determined historical decomposition method facilitated by the newly proposed LiNGAM algorithm. The findings show that the importance of China's market has improved along with its expanding economic size and rapid development in financial openness. Bissoondoyal-Bheenick et al. (2018) evaluate the stock market volatility transmission between three countries (the United States [US], China, and Australia) using a FIVAR model, provide evidence of significant bilateral causality between the countries at the market index level and across most the industries for the full sample period from July 2007 to May 2016. Aggarwal and Raja (2019) examine the cointegration among the stock markets of the BRIC (Brazil, Russia, India, and China) countries, and confirm that there is a long-term cointegrating interrelatedness between these nations. Lau and Sheng (2018) examine the inter- and intra-regional spillover effects across international stock markets in London, Paris, Frankfurt, Toronto, New York, Tokyo, Shanghai, Hong Kong, and Mumbai by using both symmetric and asymmetric causality tests. They point out that the asymmetric spillover effect is evident for price shocks originating from Asian markets and China's stock market is the least integrated of all nine markets considered.

In the African context, Sugimoto et al. (2014) examine the return spillovers in seven African stock markets (Egypt, Mauritius, Morocco, Namibia, South Africa, Tunisia, and Zambia), using a spillover index with data from September 2004 to March 2013. Specifically, the study also focuses on the interrelatedness between developed stock markets (France, Germany, China, Japan, and the US) and individual African countries during the US subprime crisis and the European sovereign debt crisis. The results report that stock markets in African nations are dramatically influenced by transmissions from international markets and are insulated from the global crisis. In addition, the authors also shed light on the aggregated transmission effects of European countries to the African markets. In a similar fashion, Giovannetti and Velucchi (2013) find that South African and US innovations affect African financial markets considerably, and China has become more intercorrelated. They use a multiplicative error fully inter-dependent model and daily data from 2005 to 2012 for several African countries, including Botswana, Kenya, Nigeria, South Africa, Egypt, Tunisia, and global financial markets, namely the US, United Kingdom, and China to analyse the interconnectedness between them.

In the international volatility literature, the standard econometric methodologies for investigating international stock market co-movements are multivariate $(\mathrm{GARCH})$ models to investigate international stock market co-movements. Andreou et al. (2013) use a quarto-variate $\operatorname{VAR}(1)-G A R C H(1,1)$ model with the BEKK (Baba, Engle, Kraft, and Kroner) representation of Engle and Kroner (1995) to discuss volatility spillovers between stock and foreign exchange markets. Huo and Ahmed (2017) employ a bivariate VAR-BEKK-GARCH model to assess the

Regional Statistics, Vol. 10. No. 2. 2020: 63-82; DOI: 10.15196/RS100203 
influence of the recently introduced Shanghai-Hong Kong Stock Connect. Wang and Wang (2010) examine stock market linkages between Greater China and the US and Japan in terms of volatility and price spillover. The estimations based on the Glosten, Jagannathan, and Runkle GJR-BEKK-GARCH model, show that volatility transmissions are stronger than price spillovers between these countries. Another interesting study is that of Gilenko and Fedorova (2014), who use a fourdimensional BEKK-GARCH-in-mean model to examine mean-to-mean, volatilityto-mean and volatility-to-volatility spillover effects for the stock markets of BRIC countries. The results are concurrent with Aggarwal and Raja (2019). In a similar vein, Li and Giles (2015) examine the linkages of stock markets across the US, Japan, and six Asian developing countries: China, India, Indonesia, Malaysia, the Philippines, and Thailand. In order to do this, multivariate GARCH-BEKK modelling of stock returns is employed to highlight the significant unidirectional shock and volatility transmissions from the US market to both the Japanese and Asian emerging markets. Kim et al. (2015), with a similar methodology, also find some evidence of financial contagion around the collapse of Lehman Brothers in September 2008.

However, the difference between short and long-term investor behaviour should be considered in a co-movement analysis. As a result, it may be significant for portfolio managers to investigate the frequency domain in order to provide a better understanding of stock co-movement behaviour at the frequency level (Aloui-Hkiri 2014). Moreover, analyses in the frequency domain are rare in the empirical finance literature. In recent years, with the improvement of financial econometrics, the increasing number of articles have employed wavelet analysis to examine the relationship between economic variables. For instance, Gourène et al. (2019) combine the generalized vector autoregressive framework and the maximum overlap discrete wavelet transform to obtain the spillovers from emerging and developed stock markets to seven African stock markets at different time scales. Aloui and Hkiri (2014) employ the wavelet squared coherence to assess the comovement in both time-frequency spaces for all the selected GCC (Gulf Cooperation Council) markets. Gupta et al. (2018) examine the links between market returns and trading volume in a time-frequency domain using a waveletbased vector autoregression technique. Their findings show that both Chinese and Indian markets display efficiency in the short to medium run. Specifically, the wavelet analysis has been used in a large number of studies on energy commodities such as Cai et al. (2017), Yang et al. (2016), Yang et al. (2017), Khalfaoui et al. (2015), Boubaker-Raza (2017), Martín-Barragán et al. (2015), Kocziszky et al. (2018), Mikhailitchenko (2016). In general, wavelet frameworks are considered as a powerful mathematical approach for signal processing that can give straightforward insight into co-movement among international stock markets via a decomposition of the time series into their time scale element.

Regional Statistics, Vol. 10. No. 2. 2020: 63-82; DOI: 10.15196/RS100203 
In this study, we illustrate strong evidence from a GARCH-BEKK model to successfully capture the volatility spillover effects between China and five frontier markets in Africa after the global financial crisis. The results reveal that Chinese and African stock markets are showing signs of integration. In addition, the results of the wavelet coherence analysis show evidence of the changing nature in the comovements of the markets over the sample period in the long term. The combination of GARCH-BEKK and wavelet techniques formally issue a more indepth and robust analysis that reinforces a better understanding of the study under examination. This type of analysis might be significant for investors, portfolio managers, and policymakers to understand the volatility spillover effects and timefrequency correlation between China and the five African stock markets. To the best of our knowledge, this is the first empirical study to combine these econometric models to shed light on the dynamic interrelatedness between the stock markets in China and Africa.

A comprehensive review of existing literature reveals a gap in the studies on interdependency among stock markets in different countries. This empirical work provides a novel approach to the literature on financial integration and liberalization. The present study differs from the abovementioned studies in that the most common methodologies used for the dynamic linkage analysis between financial markets are vector error correction models, GARCH-family models and cointegration tests, which do not imply the fundamental time-frequency changes in the lead-lag structure. Hence, this study's principal purpose is to provide a fresh new look into multiple channels of the interconnectedness between the Chinese and African stock markets. As implied in the previous paragraphs, this study contributes to the literature in several dimensions. We provide a detailed account of potential spillover effects and time-frequency correlations between China and the selected African countries. Additionally, the economic modelling is based on bivariate GARCH-BEKK models together with wavelet coherence specifications, which is an innovative characteristic of this research area.

The remainder of this paper is structured as follows. Section 2 outlines the methodology, model, and data used in this study. Section 3 discusses the estimation results and discussion. Section 4 concludes the paper.

\section{Methodology}

\section{Bivariate GARCH-BEKK Model}

The examination of volatility spillover effects between China's stock market and five frontier stock markets in Africa is implemented using the bivariate GARCHBEKK model developed by Engle and Kroner (1995). The model allows the interrelation among conditional variances and covariance, the positive conditional

Regional Statistics, Vol. 10. No. 2. 2020: 63-82; DOI: 10.15196/RS100203 
covariance matrix is generated, and it renders significant parameter reduction in the estimation.

$$
\begin{gathered}
\mathrm{R}_{\mathrm{t}}=\alpha \Gamma \mathrm{R}_{\mathrm{t}-1}+\mathrm{u}_{\mathrm{t}} \\
u_{t} \mid \Omega_{t-1} \sim N\left(0, H_{t}\right)
\end{gathered}
$$

where the return vector for the stock market variables is given by $R_{t}=\left[R_{1, t}, R_{2, t}\right]$, and the vector of the constant is $\alpha$, which presents as a $6 \times 1$ vector. The residual vector, $\mathrm{u}_{\mathrm{t}}=\left[\varepsilon_{1, \mathrm{t}}, \varepsilon_{2, \mathrm{t}}\right]$, is bivariate and a conditional normal distribution. $\Omega_{\mathrm{t}-1}$ is the market information set available at time $\mathrm{t}-1 . \mathrm{H}_{\mathrm{t}}$ represents the conditional covariance matrix and is a function of lagged cross products of errors.

Suppose for a bivariate GARCH model, the covariance matrix $H_{i, j}=\left[\begin{array}{ll}h_{11} & h_{12} \\ h_{21} & h_{22}\end{array}\right]$, and its BEKK model as follows:

$$
\begin{aligned}
\mathrm{H}_{\mathrm{t}} & =\mathrm{C}^{\prime} \mathrm{C}+\mathrm{A} \mathrm{c}^{\prime} \varepsilon^{\prime} \mathrm{A}_{11}+\mathrm{B}^{\prime} \mathrm{H}_{\mathrm{t}-1} \mathrm{~B} \\
{\left[\begin{array}{ll}
\mathrm{h}_{11, \mathrm{t}} & \mathrm{h}_{12, \mathrm{t}} \\
\mathrm{h}_{21, \mathrm{t}} & \mathrm{h}_{22, \mathrm{t}}
\end{array}\right] } & =\left[\begin{array}{ll}
\mathrm{c}_{11, \mathrm{t}} & \mathrm{c}_{12, \mathrm{t}} \\
\mathrm{c}_{21, \mathrm{t}} & \mathrm{c}_{22, \mathrm{t}}
\end{array}\right]\left[\begin{array}{ll}
\mathrm{c}_{11, \mathrm{t}} & \mathrm{c}_{12, \mathrm{t}} \\
\mathrm{c}_{21, \mathrm{t}} & \mathrm{c}_{22, \mathrm{t}}
\end{array}\right] \\
& +\left[\begin{array}{ll}
\alpha_{11} & \alpha_{12} \\
\alpha_{21} & \alpha_{22}^{\prime}
\end{array}\right]\left[\begin{array}{cc}
\varepsilon_{1, \mathrm{t}-1}^{2} & \varepsilon_{1, \mathrm{t}-1}, \varepsilon_{2, \mathrm{t}-1} \\
\varepsilon_{2, \mathrm{t}-1}, \varepsilon_{1, \mathrm{t}-1} & \varepsilon_{2, \mathrm{t}-1}^{2}
\end{array}\right]\left[\begin{array}{ll}
\alpha_{11} & \alpha_{12} \\
\alpha_{21} & \alpha_{22}
\end{array}\right] \\
& +\left[\begin{array}{ll}
\beta_{11, \mathrm{t}} & \beta_{12, \mathrm{t}} \\
\beta_{21, \mathrm{t}} & \beta_{22, \mathrm{t}}
\end{array}\right]\left[\begin{array}{ll}
\mathrm{h}_{11, \mathrm{t}-1} & \mathrm{~h}_{12, \mathrm{t}-1} \\
\mathrm{~h}_{21, \mathrm{t}-1} & \mathrm{~h}_{22, \mathrm{t}-1}
\end{array}\right]\left[\begin{array}{ll}
\beta_{11, \mathrm{t}} & \beta_{12, \mathrm{t}} \\
\beta_{21, \mathrm{t}} & \beta_{22, \mathrm{t}}
\end{array}\right]
\end{aligned}
$$

where $\mathrm{C}$ is the $2 \times 2$ upper triangular matrices. Matrix A reflects the ARCH effect of volatility, and the element of $\alpha_{i j}$ indicates the effect of market $i$ volatility on market j. By contrast, matrix B is related to the GARCH effect of volatility, the element of $\beta_{i j}$ shows the persistence of the volatility spillover between markets $i$ and $j$.

In order to estimate the GARCH- BEKK parameters under the assumption of normally distributed random errors, a quasi maximum likelihood (QLM) estimation is applied. Bollerslev and Woodridge's (1992) QML function has the following form:

$$
\mathrm{L}(\theta)=-\operatorname{Tn} / 2+\ln (2 \pi)-\frac{1}{2} \sum_{\mathrm{t}=1}^{\mathrm{T}}\left(\ln \left|\mathrm{H}_{\mathrm{t}}\right|+\varepsilon^{\prime}\left|\frac{1}{\mathrm{H}_{\mathrm{t}}}\right| \varepsilon_{\mathrm{t}}\right)
$$

where $\mathrm{T}$ is the number of observations, $\mathrm{n}$ is the number of markets, and $\theta$ is the vector of estimated parameters.

Regional Statistics, Vol. 10. No. 2. 2020: 63-82; DOI: 10.15196/RS100203 


\section{Wavelet coherence}

To supplement the GARCH-BEKK models, the wavelet coherence approach allows us to evaluate the co-movement between China and the five African stock markets in both time-frequency spaces. The wavelet technique used by Grinsted-MooreJevrejeva (2004), utilizes a bivariate framework, which is based on a continuous wavelet transform, allowing for different forms of localization. As per Nagayev et al. (2016), the wavelet method allows us to analyse correlation patterns between financial data during various regimes without having to sub-divide the data into different sample periods. A brief note on wavelet coherence is defined as follows:

$$
R_{n}^{2}(S)=\frac{\left|S\left(s^{-1} W_{n}^{X Y}(s)\right)\right|^{2}}{S\left(s^{-1}\left|W_{n}^{X}(s)\right|^{2}\right) \cdot S\left(s^{-1}\left|W_{n}^{Y}(s)\right|^{2}\right.}
$$

where $\mathrm{S}$ is a smoothing operator. Smoothing is achieved by convolution in time and scale.

$$
S(W)=S_{\text {scale }}\left(S_{\text {time }}\left(W_{n}(s)\right)\right)
$$

where $S_{\text {scale }}$ and $S_{\text {time }}$ illustrate smoothing on the wavelet scale axis and in time, respectively. The smoothing operator that we use in this study is the Morlet wavelet, therefore, Torrence and Webster's (1999) definition is the most suitable.

$$
S_{\text {time }}(W)=\left.\left(W_{n}(s) * c_{1}^{\frac{-t^{2}}{2 s^{2}}}\right)\right|_{s} \text { and } S_{\text {time }}(W)_{s}=\left.\left(W_{n}(s) * c_{2} \Pi(0.6 s)\right)_{s}\right|_{n}
$$

where $c_{1}$ and $c_{2}$ are normalization constants, $\Pi$ is the rectangle function, and the scale decorrelation length for the Morlet wavelet is 0.6

The wavelet coherence coefficient measures the local linear correlation between two stationary time series at each scale and ranges $R_{n}^{2}(s) \in[0,1]$.

$W_{n}^{X Y}(s)$ is the cross-wavelet power. This can be seen as the local covariance between the two time series at each scale. Given time series $x(t)$ and $y(t)$, the crosswavelet power can be written as

$$
W_{n}^{X Y}(s)=W_{n}^{X}(s) W_{n}^{* Y}(s)
$$

where $W_{n}^{X}(s)$ and $W_{n}^{*_{Y}}(s)$ are continuous wavelet transforms of the two time series $x(t)$ and $y(t)$. The symbol $*$ represents a complex conjugate.

The wavelet coherence phase is defined as

$$
\phi_{n}^{X Y}(s)=\tan ^{-1}\left(\frac{I\left\{S\left(s^{-1} W_{n}^{X Y}(s)\right)\right\}}{R\left\{S\left(s^{-1} W_{n}^{X Y}(s)\right)\right\}}\right)
$$

where I and R are the imaginary and real parts of the smooth power spectrum.

Regional Statistics, Vol. 10. No. 2. 2020: 63-82; DOI: 10.15196/RS100203 


\section{Data}

This study investigates volatility spillovers and time-frequency correlations between stock markets in China and five African countries including Kenya, Mauritius, Morocco, Nigeria and Tunisia. Daily stock index prices for each country are obtained from the Bloomberg Terminal. We take daily data covering the period from April 2008 to April 2019, and all indices are measured in domestic currency to avoid problems associated with transformation. The stock indices used are the Shanghai stock exchange (SSE), Nigerian stock exchange (NGSE30), Tunisia stock market (TUNINDEX), Mauritius stock exchange (SEMDEX), Kenya stock market (NSE20), and Casablanca stock exchange (CSE). Some of the reasons for our choice of these markets as case studies are that their capital stock markets are known as frontier markets (five countries in Africa) and emerging markets (China) (www.msci.com), and emerging and frontier capital markets have vastly different characteristics than developed capital markets (Hung 2019a). Recently, there have been a large number of studies pointing out that the Chinese stock market has been much related to other African markets (Kirkulak Uludag-Khurshid 2019, Lee 2019, Fang-Bessler 2018). Daily returns of the indices are calculated by taking the logarithm of the ratio of the price at time $t$ and price at $t-1$. There are 2443 observations across the markets, which is less than the total number of observations because joint modelling of the six stock markets requires matching returns. Figure 1 plots the daily stock market prices and percentage returns for the selected countries.

Table 1

Descriptive statistics of index returns from April 2008 to April 2019

\begin{tabular}{l|r|r|r|r|r|r}
\hline & \multicolumn{1}{|c|}{ China } & \multicolumn{1}{c|}{ Kenya } & Mauritius & Morocco & \multicolumn{1}{c}{ Nigeria } & \multicolumn{1}{c}{ Tunisia } \\
\hline Mean & 0.008183 & -0.006055 & 0.017603 & 0.004768 & -0.004282 & 0.025939 \\
Median & 0.065040 & -0.000873 & 0.002536 & 0.000000 & -0.013677 & 0.019410 \\
Maximum & 5.603612 & 8.634439 & 3.311208 & 4.693722 & 13.27018 & 4.108560 \\
Minimum & -8.872906 & -8.602158 & -3.232378 & -3.379210 & -15.55468 & -4.143924 \\
Std. Dev & 1.421352 & 0.691352 & 0.370234 & 0.714662 & 1.469785 & 0.534045 \\
Skewness & -0.884874 & -0.042344 & 0.116811 & 0.271715 & -0.760379 & -0.586326 \\
Kurtosis & 8.332160 & 25.04220 & 11.31375 & 5.679289 & 26.80581 & 15.05768 \\
Jarque-Bera & $3,212.946^{*}$ & $49,457.10^{*}$ & $7,041.243^{*}$ & $760.7813^{*}$ & $57,875.04^{*}$ & $14,939.22^{*}$ \\
PP test & $-47.69523^{*}$ & $-41.39208^{*}$ & $-37.16656^{*}$ & $-43.19425^{*}$ & $-41.58053^{*}$ & $-38.18816^{*}$ \\
ADF test & $-47.64320^{*}$ & $-27.68536^{*}$ & $-38.10299^{*}$ & $-43.03630^{*}$ & $-12.39489^{*}$ & $-38.13599^{*}$ \\
ARCH test & $91.71117^{*}$ & $515.2678^{*}$ & $539.3525^{*}$ & $199.4662^{*}$ & $564.1907^{*}$ & \multicolumn{6}{c}{$691.0085^{*}$} \\
Observations & 2,443 & 2,443 & 2,443 & 2,443 & 2,443 & 2,443
\end{tabular}

Notes: ${ }^{*}$ denotes significance at the $1 \%$ level. All returns are expected in percentages. The ADF and PP tests represent the augmented Dickey Fuller and Phillips Perron stationarity tests respectively. The ARCH test is employed to test the presence of the ARCH effect in the data sets.

Regional Statistics, Vol. 10. No. 2. 2020: 63-82; DOI: 10.15196/RS100203 
Table 1 depicts the preliminary statistics for the daily returns of the six stock markets as well as the statistical testing for normality, stationarity, and independence. The sample mean returns for all markets are not statistically different from zero, whereas standard deviation is relatively large in the Chinese and Nigerian markets, a common result with financial data. The measures for skewness and excess kurtosis demonstrate that the six return series are skewed and highly leptokurtic with respect to the normal distribution. The Jarque-Bera test statistics officially confirm this. In particular, all stock return series are found to be stationary at level $(\mathrm{I}(0))$ at the $1 \%$ significance level according to the PP and ADF statistics. Similarly, we examine the autoregressive conditional heteroskedasticity ARCH) effect in the data sets to employ the GARCH-BEKK model. The findings indicate the presence of the ARCH effect in the sample data, meaning that the data is suitable for further statistical analysis.

Figure 1

Daily stock prices and percentage returns from April 2008 to April 2019
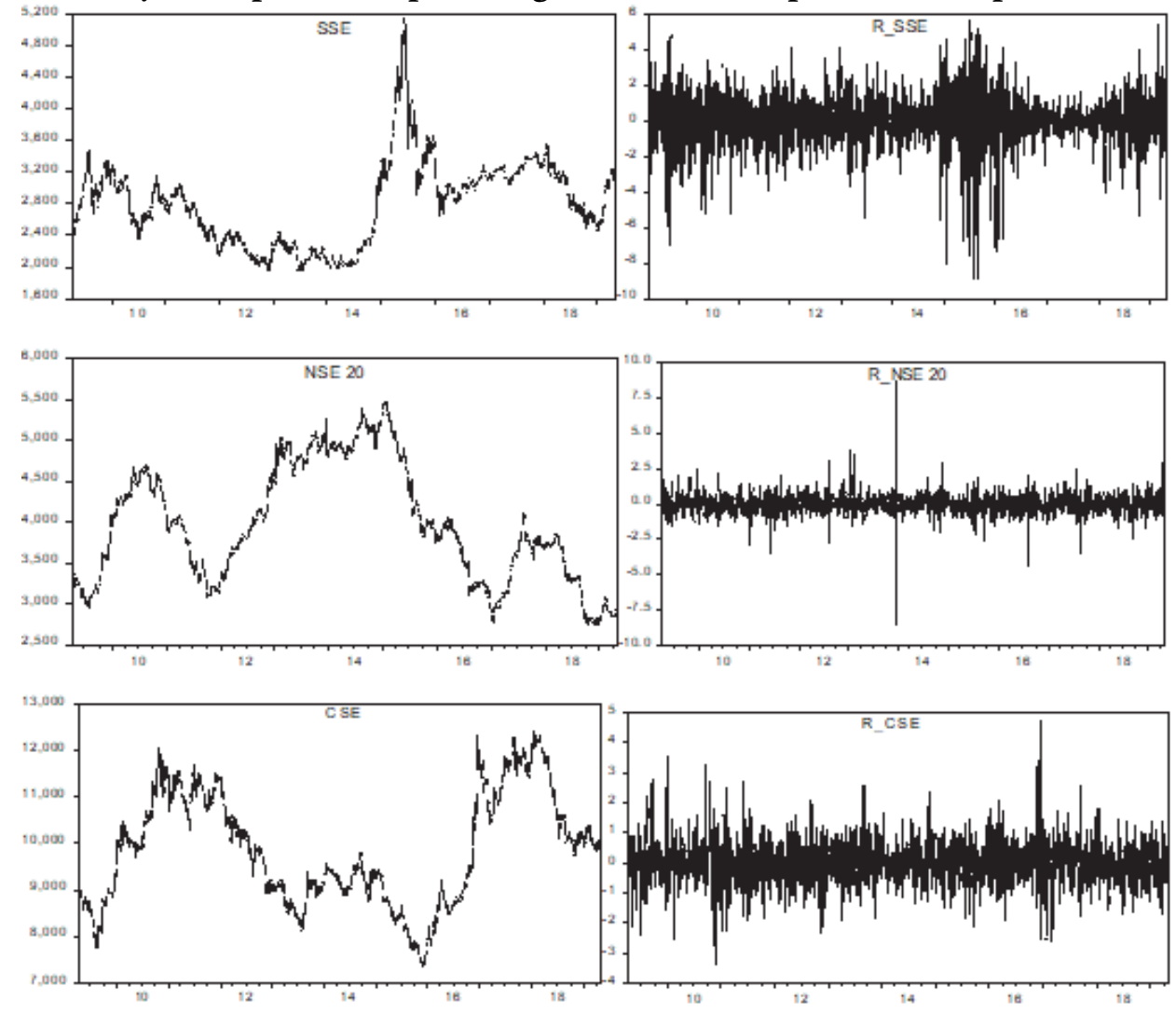

Regional Statistics, Vol. 10. No. 2. 2020: 63-82; DOI: 10.15196/RS100203 

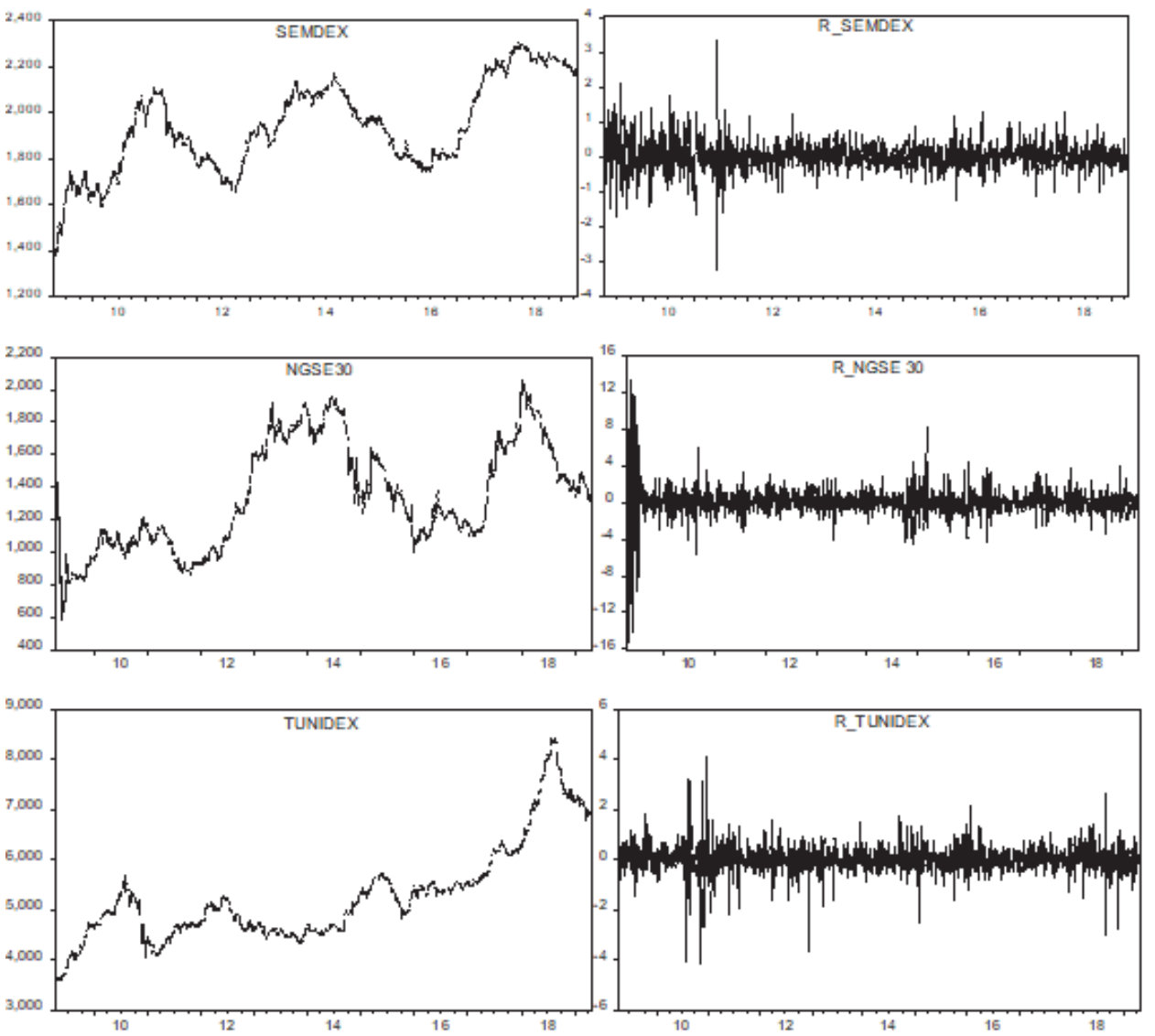

We represent the sample correlations for all markets in Table 2. It is clear that the unconditional correlation between China and Mauritius is highest (0.0452), followed by the correlation between China and Kenya in the period from 2008 to 2019. Conversely, the figure describing the correlation between China and Tunisia is negative $(-0,00321)$. Overall, the correlation coefficients among financial markets are relatively low.

Table 2

Correlation matrix between index returns from April 2008 to April 2019

\begin{tabular}{l|l|l|l|l|l|l}
\hline \multicolumn{1}{c|}{ Country } & \multicolumn{1}{|c|}{ China } & \multicolumn{1}{|c|}{ Kenya } & Mauritius & Morocco & Nigeria & Tunisia \\
\hline China & 1 & & & & & \\
Kenya & 0.00632 & 1 & & & & \\
Mauritius & 0.04526 & 0.055375 & 1 & & & \\
Morocco & 0.002019 & 0.007835 & 0.013606 & 1 & & \\
Nigeria & 0.002425 & 0.043768 & 0.035438 & 0.011222 & 1 & \\
Tunisia & -0.00321 & 0.029016 & -0.024761 & 0.040877 & -0.037174 & 1
\end{tabular}

Regional Statistics, Vol. 10. No. 2. 2020: 63-82; DOI: 10.15196/RS100203 


\section{Results}

We first represent the typical bivariate GARCH-BEKK estimation results in Table 3 as a benchmark to track the volatility transmission effects between China's stock market and five countries in Africa. We then apply the wavelet coherence technique to investigate the interrelatedness between China's market and the selected nations in Africa in a multi-scale, time-frequency domain.

\section{Volatility spillovers between China and other stock markets}

The results from the daily return series using the GARCH-BEKK model are reported in Table 3. The coefficients of $\alpha(i, i)$ and $\beta(i, i)$ are the corresponding ARCH and GARCH parameters associated with market i. Similarly, the squared GARCH parameters $\beta(i, i)$ capture the volatility responses in market $i$ to past volatility in pairs of China and each of the five selected countries (Hung 2019a). Starting from the mean equation, the first order serial dependence is insignificant in all of the markets, which means that the findings do not reveal the first moment interdependencies or price spillovers from China's market to the five African stock markets. This result is consistent with Wang and Wang (2010).

Turning to the conditional variance equation, Table 3 reports that all of the diagonal elements in matrices $\mathrm{A}$ and $\mathrm{B}$ are statistically significant above the $1 \%$ level for each pair of stock markets during the research period. The ARCH effects illustrate that the volatility of China's stock market is strongly dependent on its own past innovations. Moreover, the small size of the ARCH coefficient estimates indicates that conditional volatility has not been changed remarkably under the impulsions of return innovations (Vo-Ellis 2018). The results show strong GARCH effects, which drives the variances of each pair of concerned stock markets in our sample. As to the off-diagonal elements, which measure the second moment interconnectedness or risk spillover effects, the findings document that the parameter estimates of $\alpha_{12}$ are statistically significant for Kenya and Tunisia. This simply means that the past innovations of China's stock market significantly influence the present volatility of stock returns in Kenya and Tunisia, but not vice versa. This scenario implies that an increase in the shock to China's stock market changes the volatility of stock returns in Kenya and Tunisia after the global financial crisis. In the opposite direction, Nigeria's past shocks have a significant effect on the conditional volatility of China's stock market returns. As far as matrix B is concerned, we find a bidirectional volatility spillover between China and Mauritius throughout the sample period, and a unidirectional volatility transmission from China to Kenya and Tunisia. Additionally, there is the volatility spillover from Morocco and Nigeria to China. These spillover effects are plausible given that African stock markets are primarily traded by international investors. Briefly, the GARCH-BEKK estimation results show strong evidence of volatility transmissions from China to the five African countries during the study period.

Regional Statistics, Vol. 10. No. 2. 2020: 63-82; DOI: 10.15196/RS100203 
Table 3

GARCH-BEKK model: Stock market returns from April 2008 to April 2019

\begin{tabular}{c|c|c|c|c|c}
\hline & China-Kenya & China-Mauritius & China-Morocco & China-Nigeria & China-Tunisia \\
\hline & \multicolumn{5}{|c}{ Conditional Mean } \\
$\mu_{1}$ & 0.000421304 & 0.013643588 & 0.018238425 & 0.015781416 & 0.011780024 \\
$\mu_{2}$ & 0.011986076 & 0.054387569 & -0.013933923 & -0.013290316 & 0.033056481 \\
& \multicolumn{5}{|c}{ Conditional Variance } \\
$\mathrm{c}_{11}$ & $0.071496212^{*}$ & $0.077165824^{*}$ & $0.073806138^{*}$ & $0.062018997^{*}$ & $0.077381195^{*}$ \\
$\mathrm{c}_{21}$ & $0.029926985^{*}$ & $-0.033433332^{* * *}$ & -0.093487307 & 0.046685569 & -0.099799011 \\
$\mathrm{c}_{22}$ & $0.251922499^{*}$ & $0.090697362^{*}$ & $0.341341507^{*}$ & $0.283889737^{*}$ & $0.227194297^{*}$ \\
$\alpha_{11}$ & $0.197390770^{*}$ & $0.206487516^{*}$ & $0.213112197^{*}$ & $0.202635796^{*}$ & $0.204187878^{*}$ \\
$\alpha_{12}$ & $0.014535925^{* * *}$ & 0.001190415 & -0.002025676 & 0.008286909 & $-0.025500069^{* *}$ \\
$\alpha_{21}$ & -0.031809590 & -0.055641815 & -0.048052857 & $0.039832737^{* *}$ & 0.014493361 \\
$\alpha_{22}$ & $0.450402599^{*}$ & $0.387371280^{*}$ & $0.452775500^{*}$ & $0.436040975^{*}$ & $0.613509627^{*}$ \\
$\beta_{11}$ & $0.979579656^{*}$ & $0.976988980^{*}$ & $0.976074508^{*}$ & $0.978113657^{*}$ & $0.978024459^{*}$ \\
$\beta_{12}$ & $-0.003785203^{* * *}$ & $0.000512284^{* *}$ & 0.001576344 & -0.000892135 & $0.004512539^{* *}$ \\
$\beta_{21}$ & 0.009960703 & $0.050726558^{* * *}$ & $0.038925472^{* * *}$ & $-0.023008822^{*}$ & 0.033509599 \\
$\beta_{22}$ & $0.820984280^{*}$ & $0.878577708^{*}$ & $0.739778241^{*}$ & $0.863533786^{*}$ & $0.621490869^{*}$ \\
& \multicolumn{3}{|c|}{ Diagnostic test } & \\
ARCH & 59.96 & 71.99 & 78.95 & 75.16 & 101.76 \\
& $(0.06704)$ & $(0.06047)$ & $(0.10031)$ & $(0.03019)$ & $(0.01151)$
\end{tabular}

Notes: *, **, *** represent the $1 \%, 5 \%$, and $10 \%$ levels of significance, respectively. p-values are given in parentheses.

The last rows of Table 3 report the results of the robustness for the accuracy of the daily in-sample GARCH-BEKK estimates for the five pairs of stock markets under consideration. The ARCH effect is employed to test the conditional heteroskedasticity and the fundamental null hypothesis is that there is an $\mathrm{ARCH}$ effect in the model (Tsay 2005). The findings of the ARCH test demonstrate that there is no ARCH effect for all models considered at the $1 \%$ significance level among the five pairs. As a result, modelling the GARCH-BEKK specifications can perfectly capture the price and volatility spillovers between China and the five African stock markets. However, in order to capture the lead and lag structure amongst variables as well as to supplement our analysis, we used the cross-wavelet transform to seek regions in time-frequency space from which the series represent high common power. The divergent interconnection structures are elaborated in the following sections.

\section{Wavelet coherence}

Wavelet coherence measures how much two time series co-vary and captures timefrequency features (Khalfaoui et al. 2015). Figure 2 below describes the wavelet coherence estimation and the phase difference for all five pairs under study. Time is

Regional Statistics, Vol. 10. No. 2. 2020: 63-82; DOI: 10.15196/RS100203 
exhibited on the horizontal axis and frequency is shown on the vertical axis regions in time-frequency space where two concerned variables co-vary are located by wavelet coherence. Regions with significant relationships are represented by warmer colours (red), whereas lower dependence between variables is signified by colder colours (blue). Cold regions beyond the significant areas show frequencies and time with no dependence in the series. Both the frequency and the time intervals where the pairs of concerned variables move together significantly can be identified. An arrow in the wavelet coherence plots displays the lag phase connections between the examined variables. Because the wavelet coherence coefficient is squared, we cannot differentiate between negative and positive correlations, therefore we use the wavelet phrase differences, which reveal delays in the oscillation between the two examined time series. The two variables move together on a particular scale if the values of the wavelet phase difference range to zero. Arrows point to the right (left) when the return series are in phase (antiphase), simply meaning that they move in the same direction when the two series are in phase, and they move in the opposite direction when the two series are in anti-phase (Nagayev et al. 2016). Put another way, the series move in-phase if the wavelet phase $\phi_{X Y}\left(\lambda_{i}, t\right) \in\left[0, \frac{\pi}{2}\right]$ and the time series $\mathrm{X}$ is led by time series $\mathrm{Y}$. Conversely, if the wavelet phase $\phi_{X Y}\left(\lambda_{i}, t\right) \in\left[-\frac{\pi}{2}, 0\right]$ then $\mathrm{X}$ is leading. And if we have the a wavelet phase of $\pi$ or $-\pi$ then we have an anti-phase nexus (negative correlation). Furthermore, wavelet coherence plots can provide straightforward insights into the behaviour over time of the interactive relationships amongst the variables and across frequency. Regarding the statistical significance, it is delimitated by the bold black line for the 5\% significance level.

Overall, we can easily observe that the power dynamics of most of the regions in the cross-wavelet power spectrum are relatively low, so we can conclude that the cross wavelet recommends a weak nexus between China and the five selected financial markets. However, wavelet transform coherence is employed to recognize both frequency bands and time intervals within which a pair of series co-vary together (Afshan et al. 2018). The results of the wavelet transform coherence are presented in Figure 2.

The plot of the pair of the Chinese and Kenyan stock markets documents that the arrows are right down in the period from 2010 to 2013, suggesting that China and Kenya were exhibiting in-phase relatedness with both leading and lagging simultaneously in the market. By contrast, the arrows are left down in the small period in-between 1 to 4-week cycle during 2015 and 2018 indicating an out-phase connection with China leading. For almost the entire research period in the long scale, the study evidence shows strong coherence between both variables. In general, there is unidirectional causality from China to the Kenyan stock market. This scenario is valid for the case of the China and Mauritius pair. However, the

Regional Statistics, Vol. 10. No. 2. 2020: 63-82; DOI: 10.15196/RS100203 
arrows are right up between 2018 and 2019, which indicates that variables are in phase with China lagging. These results are in accordance with the latest findings (Ahmed-Huo 2018, Gourène et al. 2019).

We continue to consider the case of the Chinese and Tunisian stock markets. In the medium period in-between 5 to 12 -week cycle during the period from 2008 to 2010, the arrows are right down showing that variables are in-phase with China leading. However, in the 2 to 6-week cycle during the period from 2015 to 2016, the arrows are left up meaning that the series are out-phase and showing anti-cyclic effects with China leading. Further, no causality can be concluded between China and Tunisia in any small and long periods. Finally, we consider the pairs of the Chinese and Moroccan, and the Chinese and Nigerian stock markets. It is clear from the graph that there is a weak correlation between them. In particular, the findings for the long period fail to identify bidirectional causality between the variables.

Overall, the estimates of the GARCH-BEKK model together with the wavelet coherence analysis do not show notable differences in the interrelatedness between China with Kenya, Mauritius, Tunisia, Morocco and Nigeria. Our findings are consistent with the extant literature. For example, Gourène et al. (2019) report that the volatility spillover from emerging and developed stock markets to African stock markets depend on time scales and the integration in African stock markets remains weak and located at large scales. In a similar vein, Ahmed and Huo (2018) confirm that Chinese and African stock markets are showing signs of integration, and China's stock market now plays a prominent role across African stock markets. GilAlana et al. (2018) point out that evidence of cointegration is found for African countries against China. Zhou and Zhang (2012) put forward that the volatility of the Chinese stock market has had a significant influence on other markets since 2005. Recently, volatility spillover between China and Southeast Asian countries has been investigated by Hung (2019b), the findings also report that the association between China and other markets seems to be significant after the global financial crisis. Briefly, our results suggest that China is becoming a substantial economic partner of the African region. This finding is also supported by Li's (2007) study as well as the global centre hypothesis in which China, as the new economic powerhouse, will play a significant role in the information spillover and financial effect. Similarly, our result is supported by Majdoub and Sassi (2017) who provide evidence of significant positive and negative return spillover from China to selected Asian Islamic stock markets. Specifically, we consider the interconnection in terms of innovations and volatility transmission effect from five African stock markets to China, suggesting that the African stock markets are tightly integrated with China because of the increasingly close economic and trade ties between the two regions. These results are thus in line with the studies of Sugimoto et al. (2014) and Giovannetti and Velucchi (2013). These studies confirm that China and global financial markets have significant effects on the stock markets in Africa.

Regional Statistics, Vol. 10. No. 2. 2020: 63-82; DOI: 10.15196/RS100203 
Wavelet coherence results from April 2008 to April 2019

Figure 2

Wavelet Coherence: CHINA vS NIGERIA

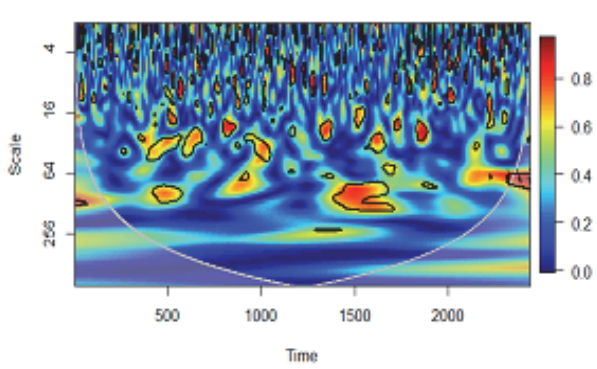

Wavelet Coherence: CHINA vs MAURITIUS

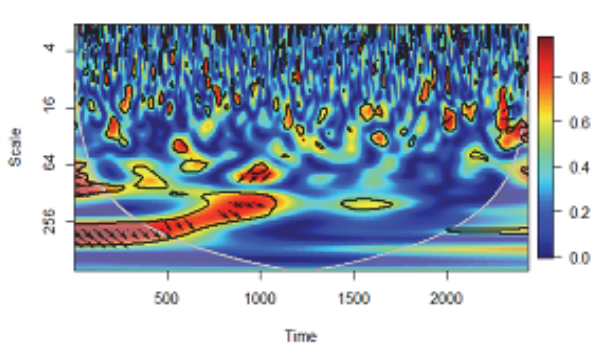

Wavelet Coherence: CHINA vs TUNISIA

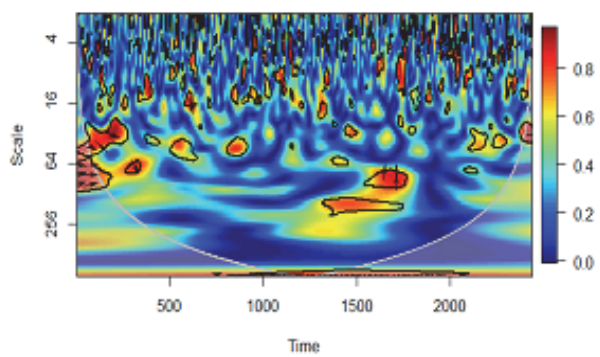

Wavelet Coherence: CHINA vs KENYA

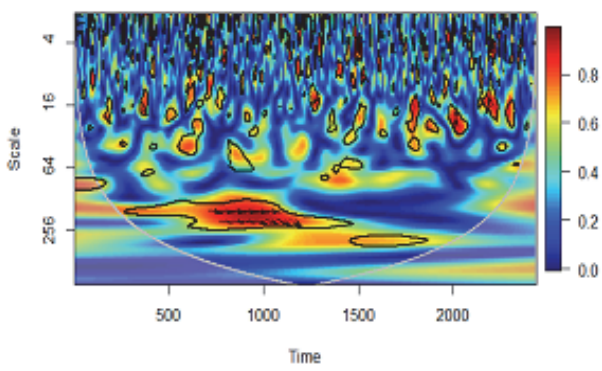

Wavelet Coherence: CHINA vs MOROCCO

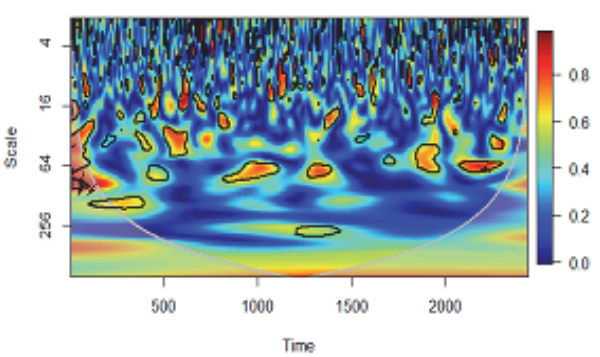

Notes: This figure presents the wavelet coherence of China's stock market (SSE) and the five frontier stock markets in Africa in pairs. Time and frequency are displayed on the horizontal (period from April 2008 to April 2019 , with $500=2008-2010,1,000=2011-2013,1,500=2014-2016,2,000=2017-2019)$ and the vertical axis, respectively. Frequency is covered in days. The warmer the colour of a region, the greater the coherence is between the pairs. The solid black line isolates the statistical significance area at the $5 \%$ level.

The documented evidence has significant implications for policymakers and market participants. First, policymakers in these countries need to be aware of the economic changes because these time series will adequately reflect on their stock market performance and interconnectedness. In addition, this study also provides positive significance for the problem of bilateral trade connectedness and stock market interaction. Market participants should pay more attention to evaluating the

Regional Statistics, Vol. 10. No. 2. 2020: 63-82; DOI: 10.15196/RS100203 
significant relationships among the markets as well as their volatility spillovers. International investors should diversify their investment portfolio and hedging in order to maximize returns and minimize risks.

\section{Conclusion}

This study investigates the volatility spillovers and time-frequency correlations between Chinese and African stock markets. The models used to examine the first and second-moment interdependencies for each pair of stock markets are GARCHBEKK models together with wavelet coherence analysis. These econometric analyses provide a fresh novel look into the time-frequency interconnection between China and five frontier stock markets in Africa (Kenya, Mauritius, Tunisia, Morocco, and Nigeria). We summarize our results as follows:

The bivariate GARCH-BEKK model might be an appropriate estimation for examining the volatility spillovers between China and other countries. Namely, we find that there is a bidirectional volatility spillover between China and Mauritius during the research period, and unidirectional volatility spillover from China to Kenya and Tunisia. Conversely, there is a volatility transmission from Morocco and Nigeria to China.

The wavelet coherence methodology shows a refinement in analysis and allows for the investigation of the time and frequency varying co-movements of the pairs of stock markets within a unified framework. We find evidence of a changing nature in the co-movements of the Chinese and African stock markets for almost all pairs over the sample period in the long term. In the short term, market interdependencies are somewhat weak at best. Interestingly, non-persistence of bidirectional causality was not found in the long-term scale. Furthermore, the arrows are pointing both right up and right down showing that our time series provide straightforward insight into in-phase interconnectedness with mutually leading and lagging the market.

Finally, the analysis conducted provides a better understanding of the timefrequency causality between stock markets in China and African countries for investors and portfolio managers who are interested in these financial markets.

\section{REFERENCES}

Afshan, S.-Sharif, A.-LOgAnAthan, N.-JAmmaZ, R. (2018): Time-frequency causality between stock prices and exchange rates: Further evidences from cointegration and wavelet analysis Physica A: Statistical Mechanics and its Applications 495: 225-244. https://doi.org/10.1016/j.physa.2017.12.033

Aggarwal, S.-RAJA, A. (2019): Stock market interlinkages among the BRIC economies International Journal of Ethics and Systems 35 (1): 59-74. https://doi.org/10.1108/IJOES-04-2018-0064

Regional Statistics, Vol. 10. No. 2. 2020: 63-82; DOI: 10.15196/RS100203 
Ahmed, A.-Huo, R. (2018): China-Africa financial markets linkages: Volatility and interdependence Journal of Policy Modeling 40 (6): 1140-1164. https://doi.org/10.1016/j.jpolmod.2018.05.002

Alden, C. (2005): China in Africa Survival 47 (3): 147-164. https://doi.org/10.1080/00396330500248086

AlOUI, C.-HKIRI, B. (2014): Co-movements of GCC emerging stock markets: New evidence from wavelet coherence analysis Economic Modelling 36: 421-431. https://doi.org/10.1016/j.econmod.2013.09.043

ANDreou, E.-MATSI, M.-SAVVIDES, A. (2013): Stock and foreign exchange market linkages in emerging economies Journal of International Financial Markets, Institutions and Money 27: 248-268. https://doi.org/10.1016/j.intfin.2013.09.003

BÉres, A.-JABlonszky, G.-LAPOSA, T.-NyikOS, G. (2019): Spatial econometrics: transport infrastructure development and real estate values in Budapest Regional Statistics 9 (2): 1-17. https://doi.org/10.15196/RS0902

BissoOndoyAl-BHEENICK, E.-BROOKs, R.-CHI, W.-DO, H. (2018): Volatility spillover between the US, Chinese and Australian stock markets Australian Journal of Management 43 (2): 263-285. https://doi.org/10.1177/0312896217717305

Bollerslev, T.-Wooldridge, J. (1992): Quasi-maximum likelihood estimation and inference in dynamic models with time-varying covariances Econometric Reviews 11 (2): 143-172. https://doi.org/10.1080/07474939208800229

BOUBAKER, H.-RAZA, S. (2017): A wavelet analysis of mean and volatility spillovers between oil and BRICS stock markets Energy Economics 64: 105-117. https://doi.org/10.1016/j.eneco.2017.01.026

CAI, X.-Tian, S.-YuAN, N.-HAMORI, S. (2017): Interdependence between oil and East Asian stock markets: Evidence from wavelet coherence analysis Journal of International Financial Markets, Institutions and Money 48: 206-223. https://doi.org/10.1016/j.intfin.2017.02.001

Cheung, Y.-Westermann, F. (2001): Equity price dynamics before and after the introduction of the Euro: a note UC Santa Cruz Economics Working Paper 473., Santa Cruz, Ca.

Donou-Adonsou, F.-Lim, S. (2018): On the importance of Chinese investment in Africa Review of Development Finance 8 (1): 63-73. https://doi.org/10.1016/j.rdf.2018.05.003

ENGLE, R.-KRONER, F. (1995): Multivariate simultaneous generalized ARCH Econometric theory 11 (1): 122-150. https://doi.org/10.1017/S0266466600009063

FANG, L.-BESSLER, D. (2018): Is it China that leads the Asian stock market contagion in 2015? Applied Economics Letters 25 (11): 752-757. https://doi.org/10.1080/13504851.2017.1363854

Gil-AlanA, L.-CARCEL, H.-ABAKAH, A. (2018): On the linkages between Africa's emerging equity markets and global markets: Evidence from fractional integration and cointegration Review of development finance 8 (2): 96-105. https://doi.org/10.1016/j.rdf.2018.11.003

Regional Statistics, Vol. 10. No. 2. 2020: 63-82; DOI: 10.15196/RS100203 
GiLenKO, E.-Fedorova, E. (2014): Internal and external spillover effects for the BRIC countries: Multivariate GARCH-in-mean approach Research in International Business and Finance 31: 32-45. https://doi.org/10.1016/j.ribaf.2013.11.002

GiovannetTI, G.-VELuCCHI, M. (2013): A spillover analysis of shocks from US, UK and China on African financial markets Review of Development Finance 3 (4): 169-179. https://doi.org/10.1016/j.rdf.2013.10.002

GOURÈNE, G.-MENDY, P.-AKE, G. (2019): Multiple time-scales analysis of global stock markets spillovers effects in African stock markets International Economics 157: 82-98. https://doi.org/10.1016/j.inteco.2018.09.001

Grinsted, A.-MoOre-JeVrejeVA, S. (2004): Application of the cross wavelet transform and wavelet coherence to geophysical time series Nonlinear processes in geophysics 11 (5-6): 561-566. https://doi.org/10.5194/npg-11-561-2004

GU, J. (2009): China's private enterprises in Africa and the implications for African development The European Journal of Development Research 21 (14): 570-587. https://doi.org/10.1057/ejdr.2009.21

GUPTA, S.-DAS, D.-HASIM, H.-TIWARI, K. (2018): The dynamic relationship between stock returns and trading volume revisited: A MODWT-VAR approach Finance Research Letters 27: 91-98. https:/ / doi.org/10.1016/j.frl.2018.02.018

Hung, N. T. (2019a): Return and volatility spillover across equity markets between China and Southeast Asian countries Journal of Economics, Finance and Administrative Science 24 (47): 66-81. https://doi.org/10.1108/JEFAS-10-2018-0106

HunG, N. T. (2019b): Equity market integration of China and Southeast Asian countries: further evidence from MGARCH-ADCC and wavelet coherence analysis Quantitative Finance and Economics 3 (2): 201-220. https://doi.org/10.3934/QFE.2019.2.201

HuO, R.-AHMED, D. (2017): Return and volatility spillovers effects: Evaluating the impact of Shanghai-Hong Kong Stock Connect Economic Modelling 61: 260-272. https://doi.org/10.1016/j.econmod.2016.09.021

ISAKOV, D.-PÉRIGNON, C. (1999): On the dynamic interdependence of international stock markets: A Swiss perspective Swiss Journal of Economics and Statistics 136: 123-146.

KHAlfaOu, R.-BOutahar, M.-Boubaker, H. (2015): Analyzing volatility spillovers and hedging between oil and stock markets: Evidence from wavelet analysis Energy Economics 49: 540-549. https://doi.org/10.1016/j.eneco.2015.03.023

KIM, B.-KIM, H.-LEE, B. (2015): Spillover effects of the US financial crisis on financial markets in emerging Asian countries International Review of Economics and Finance 39: 192-210. https://doi.org/10.1016/j.iref.2015.04.005

Kirkulak UludaG, B.-Khurshid, M. (2019): Volatility spillover from the Chinese stock market to E7 and G7 stock markets Journal of Economic Studies 46 (1): 90-105. https://doi.org/10.1108/JES-01-2017-0014

KoCZISZKY, G.-BENEDEK, J.-SZENDI, D. (2018): The impact of the 2008 financial crisis on household income and wealth in Visegrad countries Regional Statistics 8 (1): 141-167. https://doi.org/10.15196/RS080102

Regional Statistics, Vol. 10. No. 2. 2020: 63-82; DOI: 10.15196/RS100203 
Koutmos, G.-Bоотн, G. (1995): Asymmetric volatility transmission in international stock markets Journal of international Money and Finance 14 (6): 747-762. https://doi.org/10.1016/0261-5606(95)00031-3

LAU, M.-SHENG, X. (2018): Inter-and intra-regional analysis on spillover effects across international stock markets Research in International Business and Finance 46: 420-429. https://doi.org/10.1016/j.ribaf.2018.04.013

LEE, J. (2019): Asian financial market integration and the role of Chinese financial market International Review of Economics and Finance 59: 490-499.

Li, H. (2007): International linkages of the Chinese stock exchanges: a multivariate GARCH analysis Applied Financial Economics 17 (4): 285-297. https://doi.org/10.1080/09603100600675557

LI, Y.-GILES, D. (2015): Modelling volatility spillover effects between developed stock markets and Asian emerging stock markets International Journal of Finance and Economics 20 (2): 155-177. https://doi.org/10.1002/ijfe.1506

MAjDOUB, J.-SASSI, S. (2017): Volatility spillover and hedging effectiveness among China and emerging Asian Islamic equity indexes Emerging Markets Review 31: 16-31. https://doi.org/10.1016/j.ememar.2016.12.003

Martín-BarragÁn, B.-Ramos, S.-VeigA, H. (2015): Correlations between oil and stock markets: A wavelet-based approach Economic Modelling 50: 212-227. https://doi.org/10.1016/j.econmod.2015.06.010

Mikhailitchenko, S. (2016): Estimates of Net Capital Stock and Consumption of Fixed Capital for Australian States and Territories, 1990-2013 Regional Statistics 6 (2): 114-128. https://doi.org/10.15196/RS06206

NAgAYEV, R.-Disli, M.-INGHELBRECHT, K.-NG, A. (2016): On the dynamic links between commodities and Islamic equity Energy Economics 58: 125-140. https://doi.org/10.1016/j.eneco.2016.06.011

NAIDU, S.-MBAZIMA, D. (2008): China-African relations: A new impulse in a changing continental landscape Futures 40 (8): 748-761. https://doi.org/10.1016/j.futures.2008.02.007

RApHAEL, K.-Dorothy, M.-Mike, M. (2007): The Impact of China on Sub-Saharan Africa Institute of Development Studies Working Paper Issue 291., IDS, Brighton.

Sugimoto, K.-MATSuki, T.-YoshidA, Y. (2014): The global financial crisis: An analysis of the spillover effects on African stock markets Emerging Markets Review 21: 201-233. https://doi.org/10.1016/j.ememar.2014.09.004

SZNAJDERSKA, A. (2019): The role of China in the world economy: evidence from a global VAR model Applied Economics 51 (15): 1574-1587. https://doi.org/10.1080/00036846.2018.1527464

TORRENCE, C.-WeBSTER, P. (1999): Interdecadal changes in the ENSO-monsoon system Journal of climate 12 (8): 2679-2690. https://doi.org/10.1175/1520-0442(1999)012<2679:ICITEM>2.0.CO;2

Tsay, R. (2005): Analysis of financial time series (Vol. 543). John Wiley and Sons, New York.

Regional Statistics, Vol. 10. No. 2. 2020: 63-82; DOI: 10.15196/RS100203 
VO, X.-ElLIS, C. (2018): International financial integration: Stock return linkages and volatility transmission between Vietnam and advanced countries Emerging Markets Review 36: 19-27. https://doi.org/10.1016/j.ememar.2018.03.007

Wang, P.-WAng, P. (2010): Price and volatility spillovers between the Greater China Markets and the developed markets of US and Japan Global Finance Journal 21 (3): 304-317. https://doi.org/10.1016/j.gfj.2010.09.007

YANG, L.-CAI, X.-HAMORI, S. (2017): Does the crude oil price influence the exchange rates of oil-importing and oil-exporting countries differently? A wavelet coherence analysis International Review of Economics and Finance 49: 536-547. https://doi.org/10.1016/j.iref.2017.03.015

YANG, L.-CAI, J.-ZHANG, H.-HAMORI, S. (2016): Interdependence of foreign exchange markets: A wavelet coherence analysis Economic Modelling 55: 6-14. https://doi.org/10.1016/j.econmod.2016.01.022

ZHOU, X.-ZHANG, J. (2012): Volatility spillovers between the Chinese and world equity markets Pacific-Basin Finance Journal 20 (2): 247-270.

Regional Statistics, Vol. 10. No. 2. 2020: 63-82; DOI: 10.15196/RS100203 